\title{
Supported Decision-Making for Persons with Mental Illness: A Review
}

\author{
Soumitra Pathare, MD,,$^{1,2}$ \\ Laura S. Shields, $\mathrm{MsC}^{1,3}$
}

\begin{abstract}
Persons with mental illness (PWMI) are often not afforded the same opportunity to make decisions on a par with others in society. Article 12 of the International Convention on the Rights of Persons with Disabilities (CRPD) states that persons with disabilities should have equal recognition before the law and the right to exercise their legal capacity. Exercising legal capacity can mean making decisions about employment, medical or psychosocial treatment, property, finances, family, and participation in community activities. The aim of this paper is to comprehensively review the evidence on supported decision making for PWMI, both in legislation and research globally, with a focus on low- and middle-income countries (LMICs). Results reveal only a few countries have provisions for supported decision-making for PWMI, with a particular shortage of such provisions in legislation in LMICs There is also a general paucity of research evidence for supported decision-making, with the majority of research focusing on shared decision-making for treatment decisions. This review highlights the need for additional research in this area to better guide models, which can be utilised in domestic legislation, particularly in LMICs, to better implement the ideals of Article 12 of the CRPD.
\end{abstract}

Key Words: Supported decision-making, mental illness, human rights, CRPD, legal capacity

Suggested Citation: Pathare S, Shields LS. Supported decision-making for persons with mental illness: a review. Public Health Reviews. 2012;34: epub ahead of print.

\footnotetext{
${ }^{1}$ Centre for Mental Health Law and Policy, Indian Law Society, Pune, India.

${ }^{2}$ Ruby Hall Clinic, Pune, India.

${ }^{3}$ Athena Institute, VU University Amsterdam, Amsterdam, Netherlands.
}

Corresponding Author Contact Information: Dr. Soumitra Pathare at incarnapune@gmail. com; Consultant Psychiatrist at Ruby Hall Clinic, Pune, India and Coordinator of the Centre for Mental Health Law and Policy, Indian Law Society, Pune, India. 


\section{INTRODUCTION}

Making decisions is central to a person's autonomy and the essence of what is regarded as personhood, and is a crucial component in enabling an individual to have control over their life and engage with society. ${ }^{1}$ Without the ability to make decisions for ourselves, we are seen as non-persons before the law and our actions and decisions no longer have any legal force. ${ }^{1}$ In such circumstances, third parties often make decisions on behalf of persons who are deemed to lack legal capacity and guardianship is often appointed, either informally (i.e., a relative) or formally (i.e., court appointed representative). People with disabilities are thus at risk of being stripped of their decision-making abilities and rights to self-determination by having others take on the authority to make decisions for them. ${ }^{2,3} \mathrm{In}$ particular, the presence of a mental illness is often equated with a lack of decision-making capacity. ${ }^{2,4-6}$ Society has historically restricted choice to persons with mental illness (PWMI) due to an assumption of incapacity. ${ }^{7}$ As a result, institutions "took care" of many choices for PWMI, removing autonomy, responsibility, and self direction. ${ }^{7,8}$ For PWMI, having a substitute decision-making or guardianship system in place can abolish rights to self-determination and take away the opportunity to enter into transactions or contracts autonomously.

The Convention on the Rights of Persons with Disabilities (CRPD) came into force in 2008 and has created an impetus for change in disability laws (including mental health laws). The CRPD demands a paradigm shift in the disability sphere, moving from a substitute decision-making model to a supported decision-making model..$^{4-6,9-14}$ Article 12 has been called the core of the CRPD and states that all persons with disabilities (PWD) should have equal recognition before the law. ${ }^{14-16}$ It declares that PWD should have both the recognition of their rights, legal capacity and the right to exercise this legal capacity. ${ }^{6,17,18}$ In practical terms, exercising legal capacity means making decisions for oneself in all areas of life including medical treatment, housing, employment, relationships, finances, children, family planning, and property. The CRPD recognizes that there are times when PWD may require support in making decisions and that depending on the course of the disability or illness, varying levels of support may be needed. ${ }^{6,18}$ Accessing support, regardless of its form, is central to the recognition of being equal and full citizens before the law. ${ }^{3}$ Countries are expected to take measures to support PWD to exercise their legal capacity, which are tailor-made to the person's circumstances and preferences; apply for the shortest amount of time possible; provide safeguards to prevent abuse; and are regularly reviewed by a legal authority. ${ }^{19}$ 
In most countries, mental health legislation does not include provisions for PWMI to exercise legal capacity. A number of laws still adopt a paternalistic approach with the stated purpose of protecting the individual and society from harm. ${ }^{5,20}$ This protection has been linked to the historical view that PWMI are dangerous to others ${ }^{21}$ or violent, ${ }^{22}$ leading the state to adopt a protective role. Early laws concerned with mental health were often penalizing and concerned with taking the individual away from society, ${ }^{21}$ frequently prescribing institutionalised treatment and guardianship as the solution and as a means of protection. ${ }^{5,6}$ Fortunately, mental health reform in a number of countries has led to new mental health legislation that better promotes treatment in the community and inclusion of PWMI in society. Despite mental health reform, however, guardianship and substituted decision-making systems are still the prevailing norm in many countries and jurisdictions for PWMI.

Terminology used to describe decision-making capacity as it relates to mental illness differs substantially across jurisdictions, countries and even between disciplines of law and health. Decisions can be made in a number of ways in both law and health. Decisions can be made autonomously or by electing powers of attorney or writing advance directives, or by having court-appointed mentors or legal representatives or by having other supports (e.g., information aids, decision aids, peer support) or by having a substitute decision-maker. For the purposes of this review, we consider guardianship as a form of substituted decision-making where a decision maker is appointed to make decisions on behalf of a person believed to lack mental capacity.6 Guardianship can vary in its levels of decision-making power; for example, guardianship can be limited, partial or full (also known as plenary). While limited and partial guardianship are not ideal for realising legal capacity and autonomy, they allow an individual to retain some decision-making abilities in other areas of life, thus these levels of guardianship are preferred over full guardianship. ${ }^{6}$

The concepts of mental and legal capacity differ and hold different meanings. Legal capacity can be viewed as a person's capacity to have rights and exercise these rights without discrimination. ${ }^{3,15,23}$ In contrast, mental capacity can be seen as the ability to understand incoming information, considering the harms and benefits of making or abstaining from a decision, and the ability to communicate the decision to others. ${ }^{23,24}$ The correlation between the two definitions is that the cognitive requirements for mental capacity are also needed to exercise legal capacity. ${ }^{23}$ Frequently, health or law professionals decide on both legal and mental capacity and it is often established prior to involvement from the legal system. ${ }^{24}$ However, even an individual unable to go through this decision-making process should 
still have the right to retain full legal capacity, instead accessing support where necessary to be able to reach the same decision autonomously. ${ }^{23}$

Research on decision-making for PWMI has been largely restricted to the medical domain, focusing primarily on treatment decisions. There is limited research outside this sphere, which test or evaluate supported decision-making models and assess legal outcomes as related to mental illness. Research has predominantly focused on shared decision-making. Shared decision-making has not been precisely defined in the literature, ${ }^{25,26}$ although it has been extensively researched ${ }^{27-34}$ (for review see ${ }^{26,34-41}$ ). In an attempt to clarify the concept of shared decision-making, Makoul and colleagues $^{42}$ posited that for a decision to be shared, it must involve at least two participants, have shared information and the decision must be made and agreed upon by all parties. Montori and colleagues ${ }^{43}$ subsequently added to this conceptual definition of shared decision-making by stating (specific to decision making in health care) that a decision is only shared if there is an ongoing partnership and collaboration between the health care

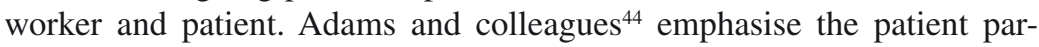
ticipation angle of shared decision-making, highlighting that patients should have accessible information, enabling them to participate in an active and meaningful way.

Shared decision-making enables an individual to exercise partial autonomy over decisions and has been positioned as an intermediate option between paternalistic models and informed choice models ${ }^{35}$ and has been associated with improvements in patient satisfaction, treatment adherence, and improved health outcomes (e.g., reduction of severity of symptoms). ${ }^{34,45-48}$ Conversely, supported decision-making is broader, and can consist of organisations, networks, provisions or agreements with the aim of supporting and assisting an individual with a mental illness to make and communicate decisions. ${ }^{6,23}$ In supported decision-making, the individual is always the primary decision maker, but it is acknowledged that autonomy can be communicated in a number of ways, thus provision of support in different forms and intervals can assist in the expression of autonomous decisions. Supported decision-making enables the individual to retain legal capacity regardless of the level of support needed. ${ }^{3}$ Forms of supported decision-making can therefore include advance directives, enduring powers of attorney, health care proxies, arrangements for financial decisions (e.g., payee regimes, banking systems), nominated representatives, and/or personal ombudsmen. These forms of support are more formal and offer less autonomy to PWMI on the support spectrum than less formal forms of support. ${ }^{6}$ Less formal but equally important forms of support can consist of support networks of family and friends and peer support. 
Research has extensively focused on advance directives which are defined as a supportive tool that specify a person's wishes and preferences for treatment decisions for the future when he or she loses decision-making capacity. ${ }^{49-51}$ In advance directives, the wishes of the client are expressed and based only on circumstances wherein the client loses decision-making capacity. ${ }^{49,51}$ Advance directives, while a valid support tool and a form of supported decision-making, offer less autonomy and can transition into a form of substituted decision-making depending on the authority of the other person involved in the decision-making process. Furthermore, these tools are often not offered to persons with severe mental illness as they are seen by professionals to lack capacity. ${ }^{3}$

Despite the CRPD's exhortation for supported decision-making, there has been resistance, primarily due to the assumption that PWMI are unable to make the right decision and are not aware of their best interests. This is based on the "outcomes" approach to legal capacity, which infers one's capacity from the outcomes of decisions they make. This means that there are "right" and "wrong" decisions, and someone only has capacity if they can demonstrate that they can make "right" or reasonable decisions. ${ }^{2}$ The bias in this approach lies in the fact that it assumes PWMI must make "right" and reasonable decisions to be considered to have capacity, and it does not afford PWMI the right to make mistakes or wrong decisions (and to subsequently learn from experience) like others in society. ${ }^{2}$ Furthermore, persons without disabilities also solicit advice from family and professionals prior to making a decision-particularly health care decisions. In this sense, the concept of supported decision-making for people with disabilities only re-emphasises the norm of seeking advice and input when making an important decision.

As no countries have fully implemented Article 12 of the CRPD, ${ }^{1,52}$ there is a need to review what progress has been made to date, particularly in low- and middle-income countries (LMICs) where constrained resources required to shift legal and social sectors to a model of supported decisionmaking may be problematic. Reviewing the evidence and legislation will assist in guiding the research findings, delineate crucial areas for future research, and draw on the efficacy of support aids for PWMI within legislative frameworks to make the "paradigm shift" of the CRPD a reality in practice. Therefore, the aim of this paper is to review the literature on supported decision-making processes in light of Article 12 of the CRPD, examine best practices in supported decision-making internationally and point towards how components of supported decision-making can be implemented. 


\section{METHODS}

\section{Study selection}

As this review focuses on supported decision-making as it relates to mental illness and legal capacity, we review shared decision-making only briefly and synthesise the evidence in a way that might inform supported decisionmaking models. Studies in decision-making are not always conducted as randomized controlled trials (RCTs), and restricting inclusion to a particular study design could substantially limit relevant data included in the evidence base. We therefore included RCTs, quasi-experimental studies, and qualitative studies. We also included grey literature (policy documents, legislation, unpublished presentations, reports) for the portion of the review identifying legislation for supported decision-making. We included all studies as long as at least 50 percent of the sample population had a mental illness and the intervention or research aim focused on decision-making for this population. We excluded studies if they focused on support tools which were not fully defined to be "supportive" (i.e., advance directives, nominated representatives, powers of attorney, health care proxies); populations with mental retardation, intellectual disabilities, Alzheimer's, dementia or cognitive impairment, or focused on patients with health conditions other than mental health problems. There were no language restrictions for this review. Outcomes of interest for this review included patient satisfaction, health care outcomes (e.g., hospitalization rates post-intervention, severity of symptoms, medication adherence), effective supported decision-making models, legislation including provisions on supported decision-making (for grey literature). Relevant settings for the review of the research literature were community, primary, secondary, tertiary health care and social care settings (including inpatient psychiatric facilities).

\section{Search Strategy}

In order to maximize the number of possible retrieved studies from the searches, we conducted searches incorporating a number of terms related to decision-making for PWMI. All search terms were combined with AND "mental health" OR "mental illness". We conducted the search using the following terms: "assisted decision-making," "shared decision-making", "facilitated decision-making" and "supported decision-making." We broadened these search terms as we recognized that searching only for shared decision-making would focus primarily on medical treatment decisions, and although relevant, we wanted to additionally include articles focusing 
on other circumstances beyond medical decisions. For the legislative component of the review, we reviewed laws from any country regardless of its income level, as long as it incorporated provisions for supported decision-making for PWMI or included alternatives to guardianship and substituted decision-making systems. We searched in the following databases: PubMed, MEDLINE, PsycINFO, and Cochrane Library. References were searched from 1950 up until 2012. We also searched through reference lists of included studies to identify any additional references for potential inclusion that our searches might have missed. These additional references were searched in Google Scholar.

\section{Data collection}

From each study, we extracted the study design, setting, participant information, interventions (where appropriate), results, and limitations of the study. Both authors looked through the reference lists of included studies to identify any additional references that may have been missed by the searches. If relevant for inclusion, we obtained the abstract from the reference, and if relevant, obtained the full-text of the reference for review.

\section{Results}

Our initial search yielded 8,041 references in total. Of these, we assessed those based on titles and abstracts, which yielded 511 potentially relevant studies, of which we obtained the full-text. After applying our inclusion criteria, we included 26 studies (13 studies for the research review and 12 for the legislation review). From the reference lists of the included studies, we identified an additional 134 potentially relevant studies, of which 30 were included in both the legislative and research review. A flow chart of the sifting strategy is shown in Figure 1. Common reasons for exclusion of studies include: the intervention was beyond the scope of this review (e.g., end-of life decision-making interventions, decision-making interventions aimed at physical health problems like diabetes or cancer); topic of paper focused on legislation outside of decision-making and legal capacity (e.g., on treatment orders or discharge from treatment); the population of focus in the paper was beyond the scope of this review (e.g., focused on patients with Alzheimer's or dementia or mental retardation). In total, we reviewed 25 research studies and 30 papers providing information on legislation in 16 countries. 


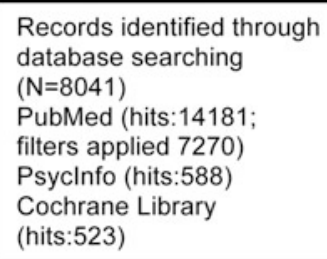

PubMed (hits: 14181;

filters applied 7270)

Psyclnfo (hits:588)

Cochrane Library

(hits:523)

Records after duplicates removed $(\mathrm{N}=5244)$

Records screened full-text $(\mathrm{N}=511)$

References included $(\mathrm{N}=26)$

Research review $(\mathrm{N}=13)$

Legislation review $(\mathrm{N}=12)$
Records identified through other sources $(\mathrm{N}=134)$
References excluded $(\mathrm{N}=104)$

References included $(\mathrm{N}=30)$

Research review $(\mathrm{N}=12)$ Legislation review $(\mathrm{N}=18)$.

Fig. 1. Flow chart of study selection.

\section{LEGISLATION REVIEW}

A number of countries, all upper middle- or high-income, include provisions for supported decision-making in national legislation (see Table 1). One result emerging is that advocacy services and/or community organisations (e.g., the Canadian Association for Community Living) are influential in assisting PWMI in arranging supported decision-making agreements. In the United States, there is strong support for psychiatric advance directives (PADs) to PWMI in 25 states, however our search did not identify any state legislation referring to supported decision-making beyond provisions for PADs. In Canada, five provinces (British Columbia, Yukon Territories, 


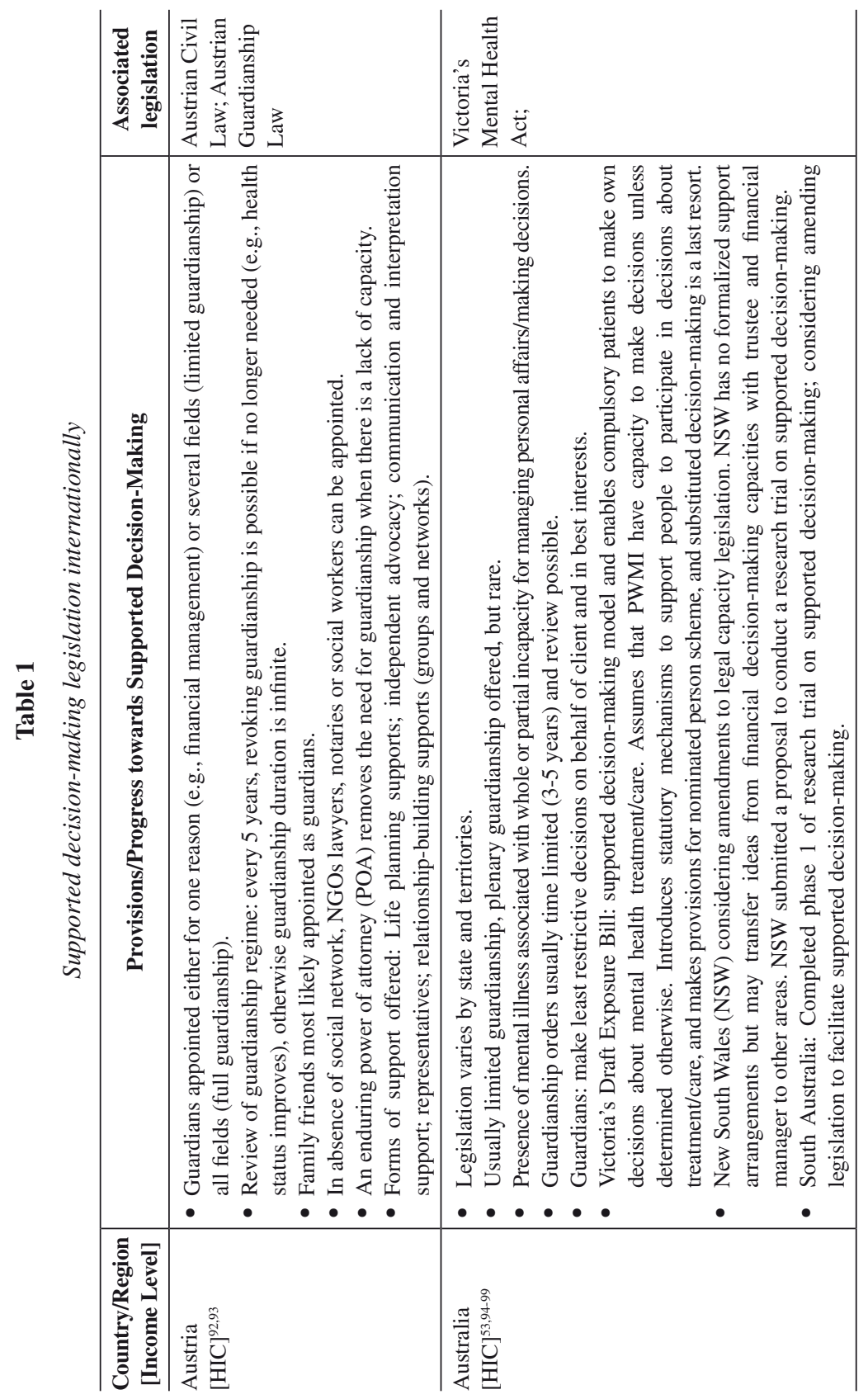




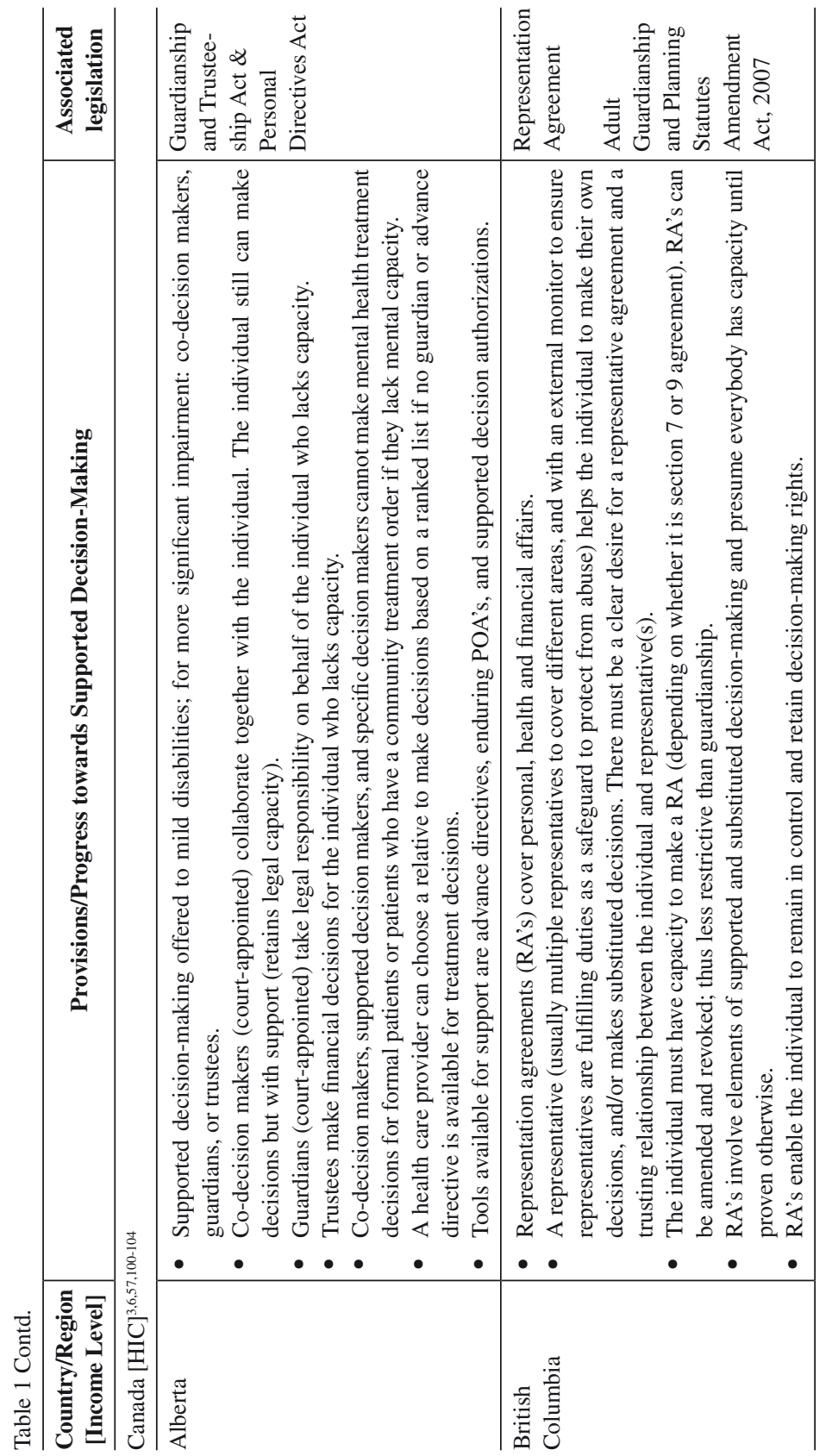




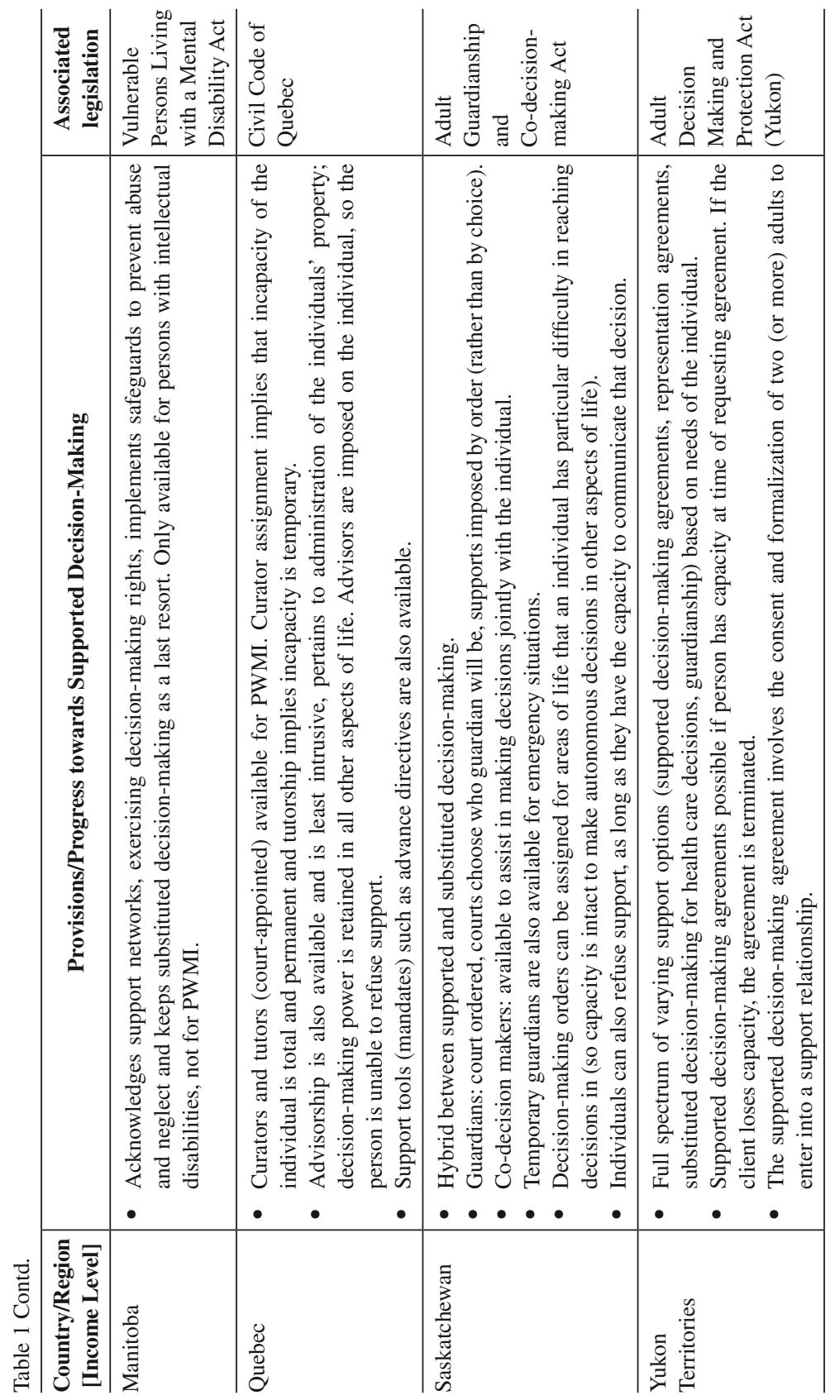




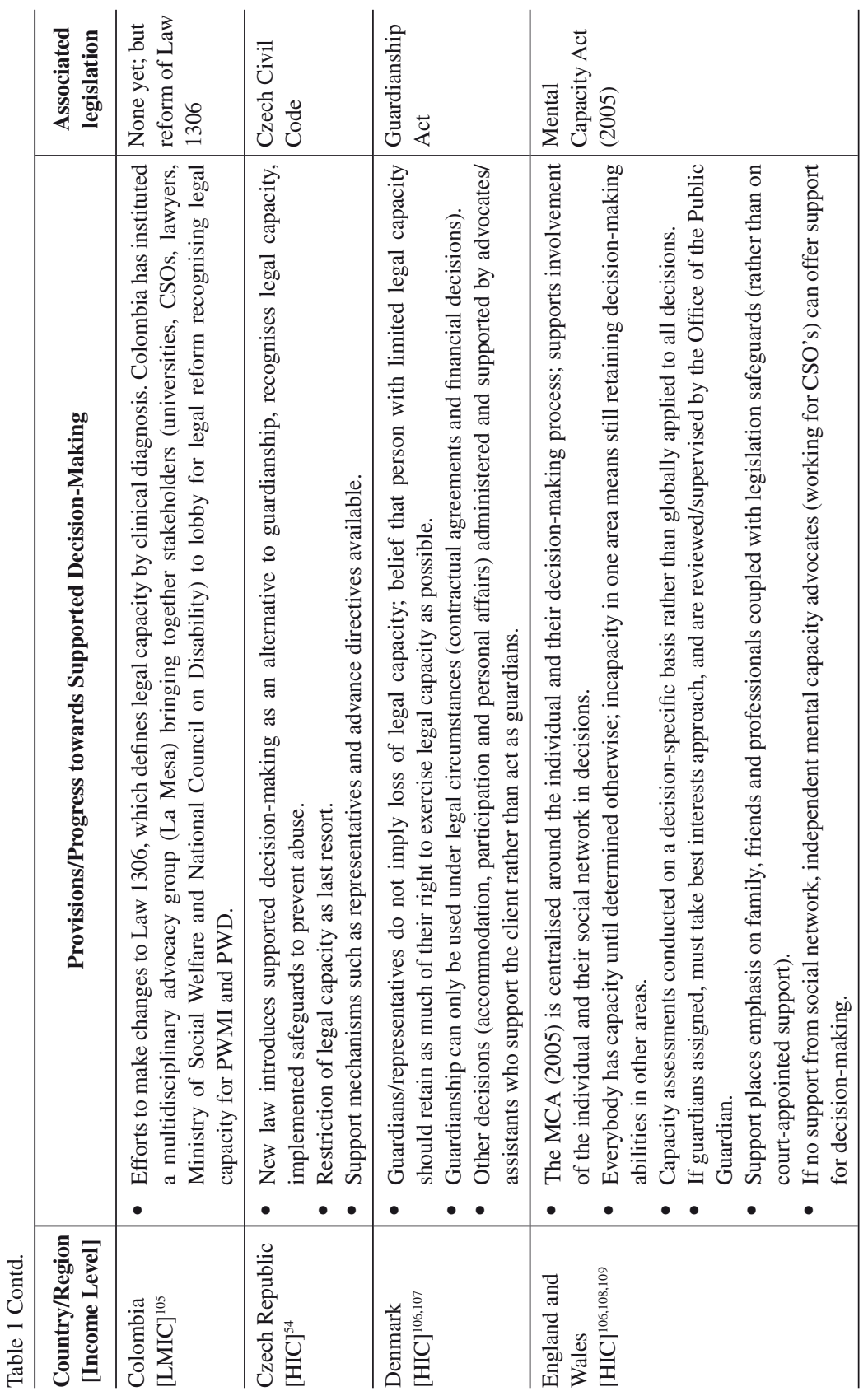




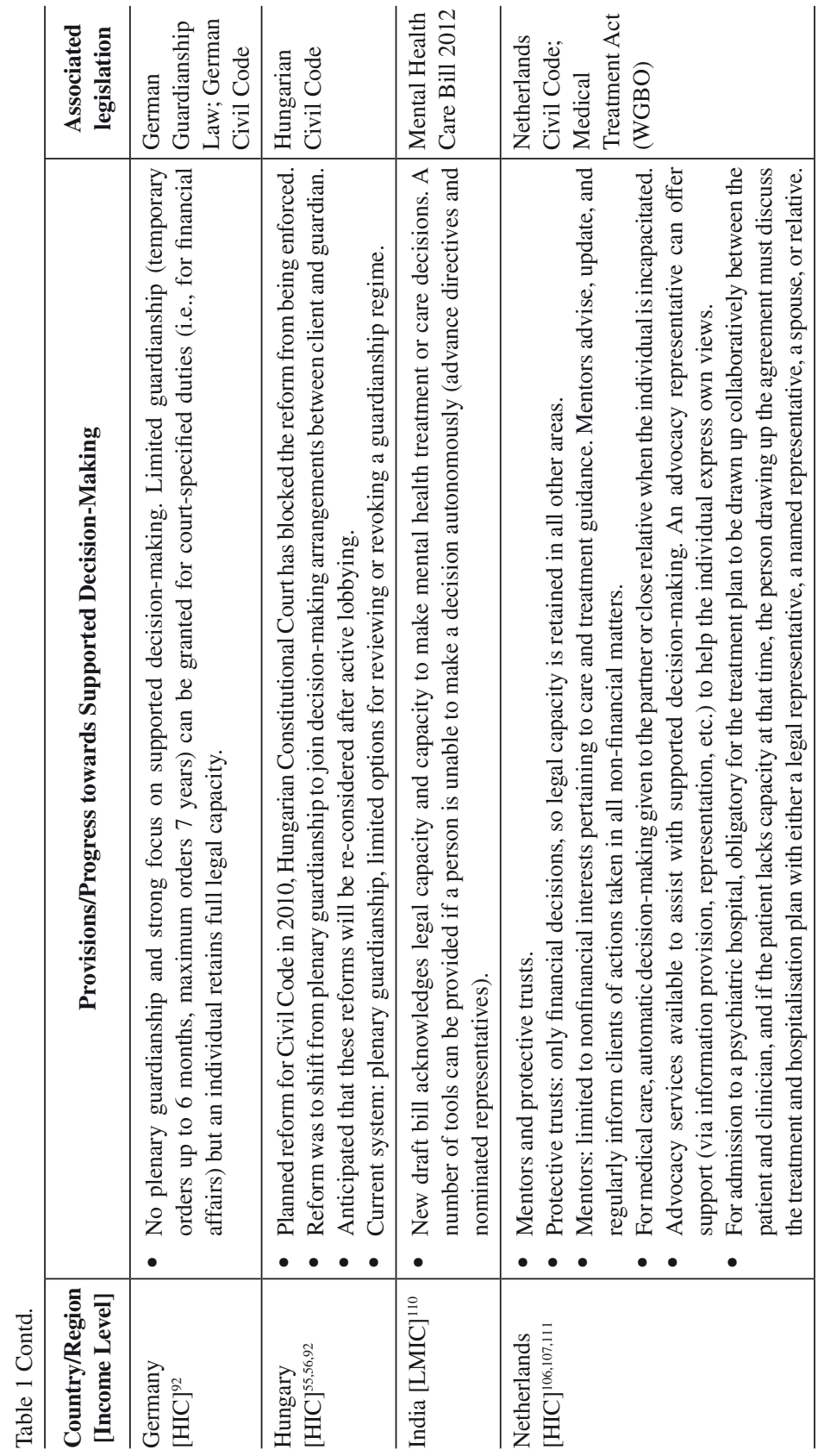




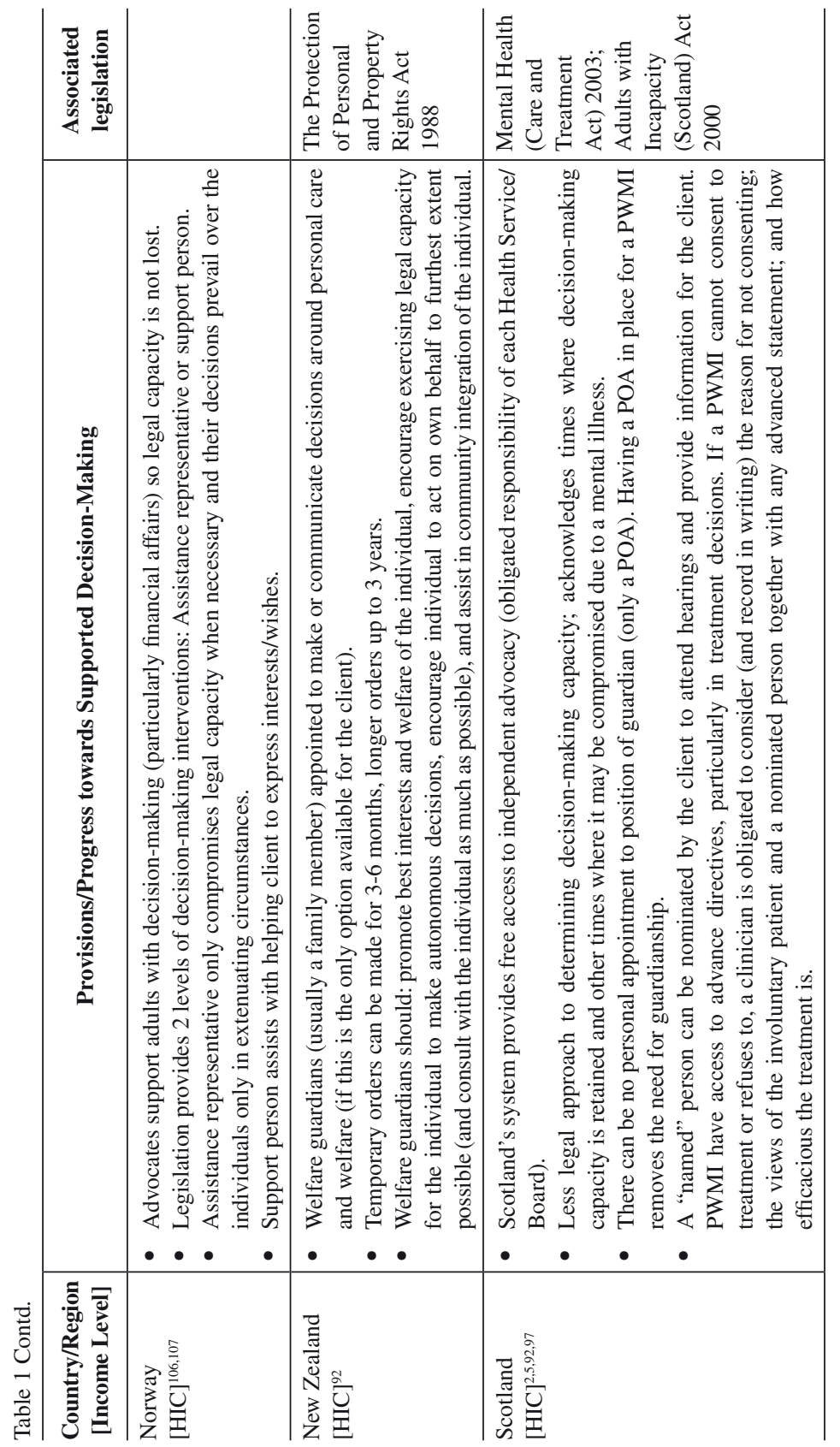




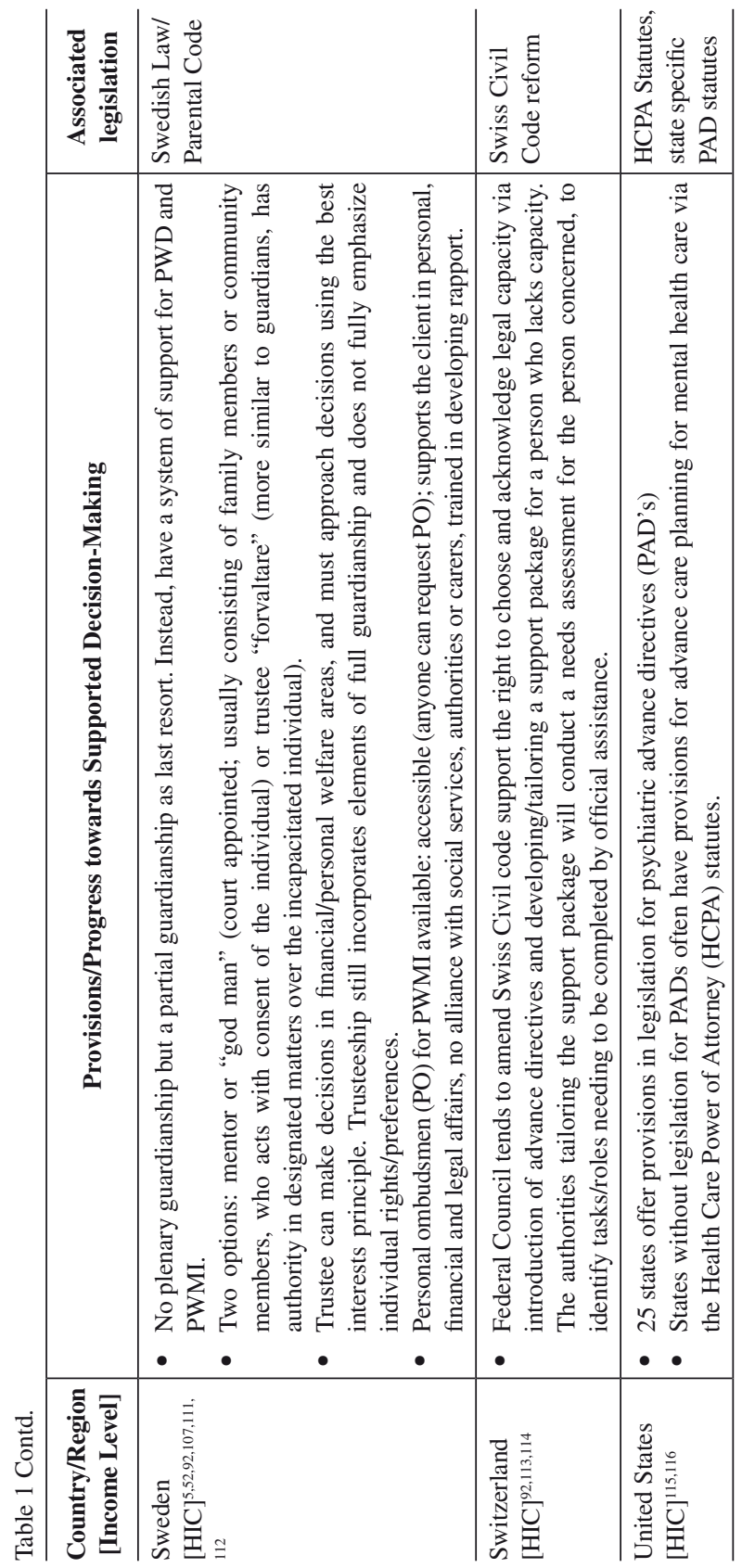


Alberta, Saskatchewan, Quebec and Manitoba) have legislation providing for varying forms of supported decision-making. ${ }^{6}$ Canada and Australia, although having signed and ratified the CRPD and having provisions for varying forms of support for exercising legal capacity, have both entered a reservation on Article 12 of the $\mathrm{CPRD}$, interpreting compulsory treatment and fully-supported or substituted decision-making as permissible under the CRPD, but only as a last resort. ${ }^{53}$ Scotland's progressive Mental Health Act and the United Kingdom's Mental Capacity Act have both developed a Code of Practice to assist service users and carers on interpreting these Acts, which is particularly useful when it comes to outlining decisionmaking capabilities. ${ }^{2,5}$ In 2012, The Czech Republic enacted a new civil code introducing supported decision-making and stating that restrictions of legal capacity are a last resort. ${ }^{6,54}$ Germany has also made use of supported decision-making agreements in various forms for PWMI. ${ }^{6}$ The introduction of a "friend" or "mentor" appointed by the court has become common in a number of European countries, such as Germany, Finland, Sweden and Austria. Friends/mentors are appointed to an individual after a capacity assessment finds the individual to lack capacity. The friend/mentor has authority to make substitute decisions, is expected to elicit the preferences of the client, and can also allow for the individual to make autonomous decisions in certain areas of life. ${ }^{52}$ This arrangement has been viewed as a middle ground between autonomous and substituted decision-making. ${ }^{3}$

\section{ON THE WAY TO REFORM}

Advocacy measures to implement Article 12 of the CRPD are strong, though legal reform has yet to take place. ${ }^{52}$ Guardianship law reform is occurring in the Czech Republic, Hungary, France, Ireland, Portugal, Slovakia and Slovenia. Several South American countries like Colombia also offer either plenary guardianship or assistance to make decisions, where the individuals' decision is taken into account along with a third party. The Hungarian Government, after plans in 2009 to abolish plenary guardianship and offer supported decision-making as an alternative, declined to enact the new reforms in $2010 . .^{55,56}$ Norway and Germany have mixed systems, offering both support and substitution decision-making. ${ }^{57}$ Sweden has abolished plenary guardianship and offers a system of support services in favour of the support paradigm ranging from mentors to trustees allocated to support PWD. Mentors can be family members, members of the community or professionals who act only with consent of the person receiving support. Trustees, however, are similar to guardians but the individual retains the right to vote..$^{52,58}$ 


\section{RESEARCH REVIEW}

\section{Supported decision-making in high-income countries (HICs)}

Few studies have assessed supported decision-making beyond treatment decisions, such as how supported decision-making impacts legal capacity and other life decisions. One study looked at having choice about housing and receiving support to autonomously decide about housing in the community. Srebnik et al. found that perceived autonomy to decide about housing had a substantial impact on psychological well-being. ${ }^{8}$ Other authors have discussed financial capacity in persons with schizophrenia, recommending the use of advance directives to outline preferences and processes with regards to financial matters during periods of both capacity and incapacity. ${ }^{59}$ Another study in Australia ${ }^{60}$ looked at the impact of supported decision-making. Results revealed that out of 22 adults, eight $(36 \%)$ wanted to receive support in several areas of their life (e.g., choosing services, housing, medical procedures). Social exclusion was identified as a barrier to supported decision-making, as three of 22 participants had nobody they could nominate in their life as a supporter, though they were keen to have support. ${ }^{60,61}$ Participants believed that an advocate or multidisciplinary team would be best to provide support for mental health care decisions, a solicitor for legal decisions, and a friend or relative for day-to-day matters. Another study conducted by Amnesty International in Ireland ${ }^{62,63}$ revealed that after interviewing eight clients, all were unanimously in favour of writing advance directives and expressed strong ideas in favour of supporteddecision making. Participants acknowledged that emotional distress can impact decision-making capacity, and capacity can be further reduced by social and environmental factors, such as lack of available treatment options, lack of trust in an information provider, and inaccessible information. The participants also articulated that incapacity as it relates to mental illness is a partial rather than a total phenomenon. They stressed that assessments of capacity need to take into account how much the individual at that particular time is able to contribute to their own decision-making rather than making assumptions that they are incapable due to mental illness or relying on past episodes to infer current capacity. The findings from Australia and Ireland highlight the need for a strengths-based approach in accord with a social model of disability to build up the decision-making confidence of the individual. 


\section{Shared decision making in mental health care}

While a number of reviews have assessed shared decision-making we chose to review primary studies and not conduct a review of reviews. Despite the extensive research on shared decision-making, we were unable to identify any studies focusing on shared decision-making interventions in LMICs; therefore our review is limited to studies conducted in HICs (Table 2).

Shared decision-making interventions have shown mixed results. Some authors have found that shared decision-making interventions had some impact on reducing the severity of substance-related and/or psychiatric problems but did not impact quality of life. ${ }^{64,65}$ Another study found shared decision-making to have a significant impact for clients with a mental illness even when deciding on secondary decisions like lifestyle behaviours. ${ }^{66}$ Mahone (2008) found that participation in shared decision-making was associated with better medication adherence rates, ${ }^{65,67}$ while a recent study found that a computerized shared decision-making tool had no impact on medication adherence in community outpatient settings. ${ }^{68}$

\section{Preferences in decision-making}

Common across the majority of the studies is the finding that PWMI have a higher desire for treatment decision-making than other groups within general medicine. ${ }^{39,69-71}$ In addition, participants in a number of studies declared that they had a clear desire for greater participation in decision regarding their psychiatric care compared to the current care they were receiving..$^{39,65,67,70}$ To illustrate, in one study, 82 percent of participants preferred a collaborative relationship with their health care provider, however only 70 percent experienced this collaboration. ${ }^{65}$ Interestingly, participants articulated a clear idea of how and when to prioritise autonomy in decision-making and when to consult or defer the decision to health care professionals. One study ${ }^{72}$ interviewed participants who endorsed a twostep process of decision-making; first prioritising autonomy and if autonomy was not possible, case managers were consulted to help make a decision.. The desired autonomy for decision-making varied by type of decision: for example, with medication choices, 77 percent prefer either autonomous or shared roles regarding their choices. ${ }^{44}$ Preferences for decision-making also vary when it comes to who patients prefer to make health care decisions for them. Participants in one study ${ }^{70}$ wished for collaborative decision-making with health care professionals for medication decisions, autonomous decision-making for psychosocial treatment and a passive role in decision-making with their general health care providers. 


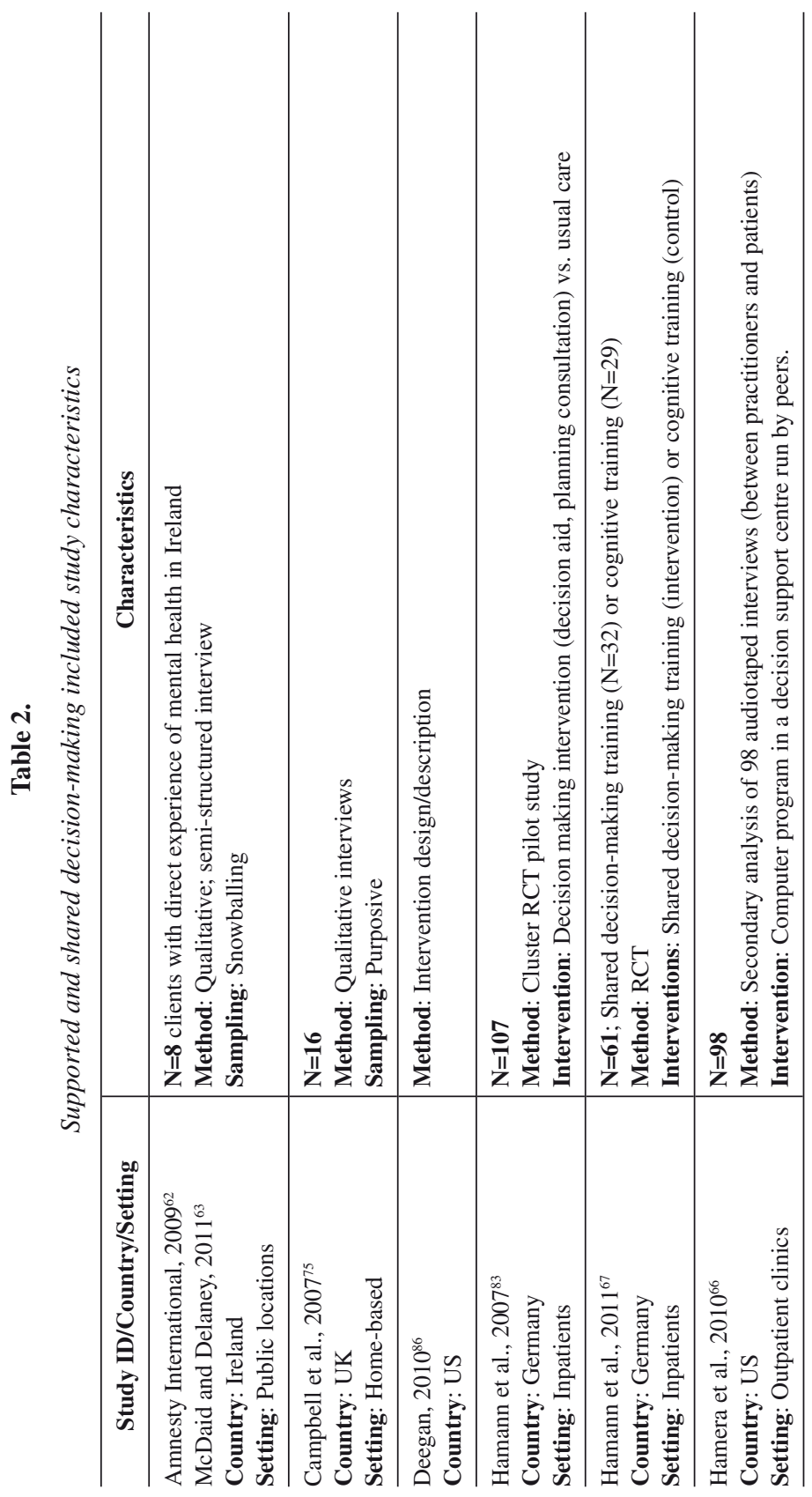




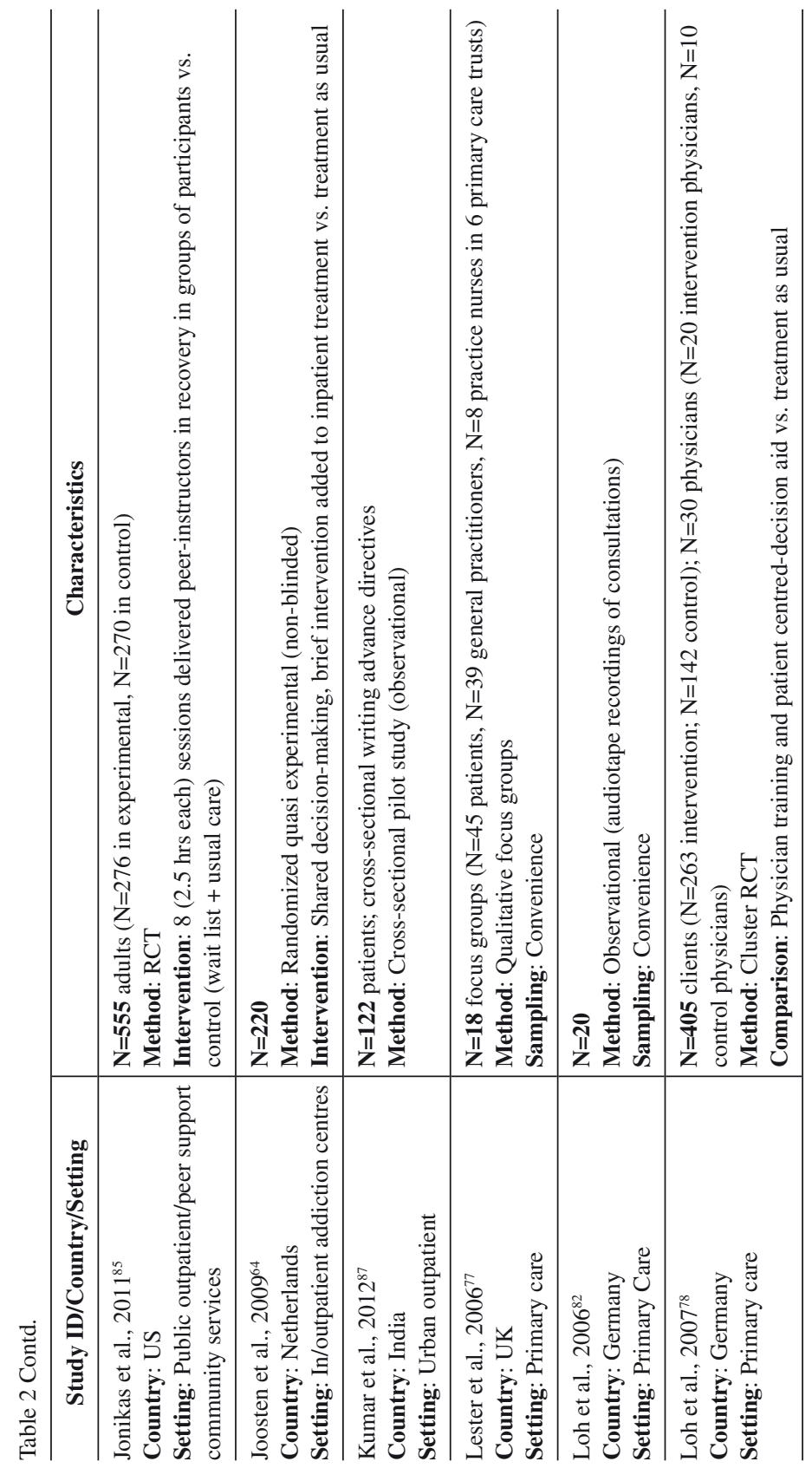




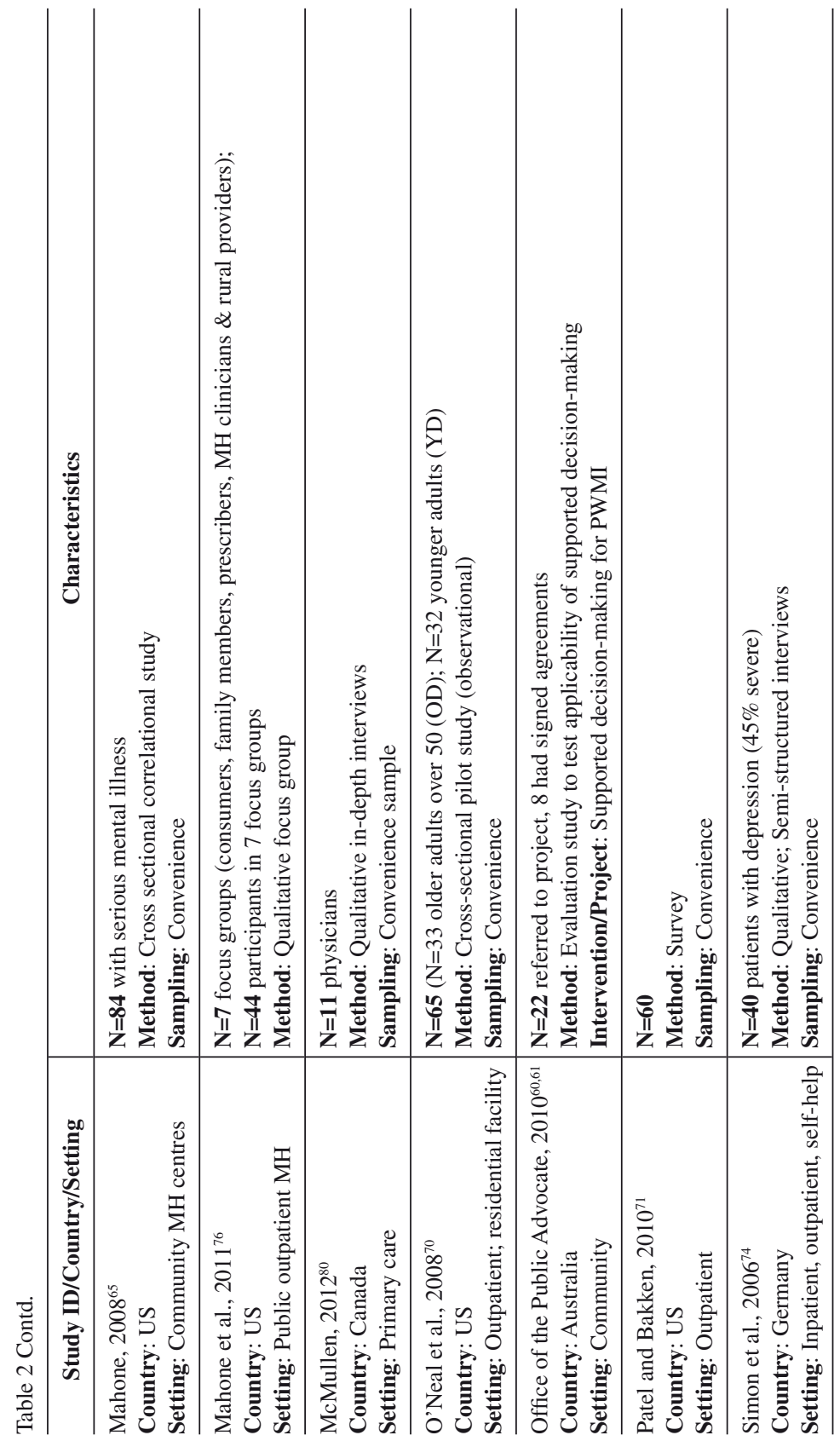




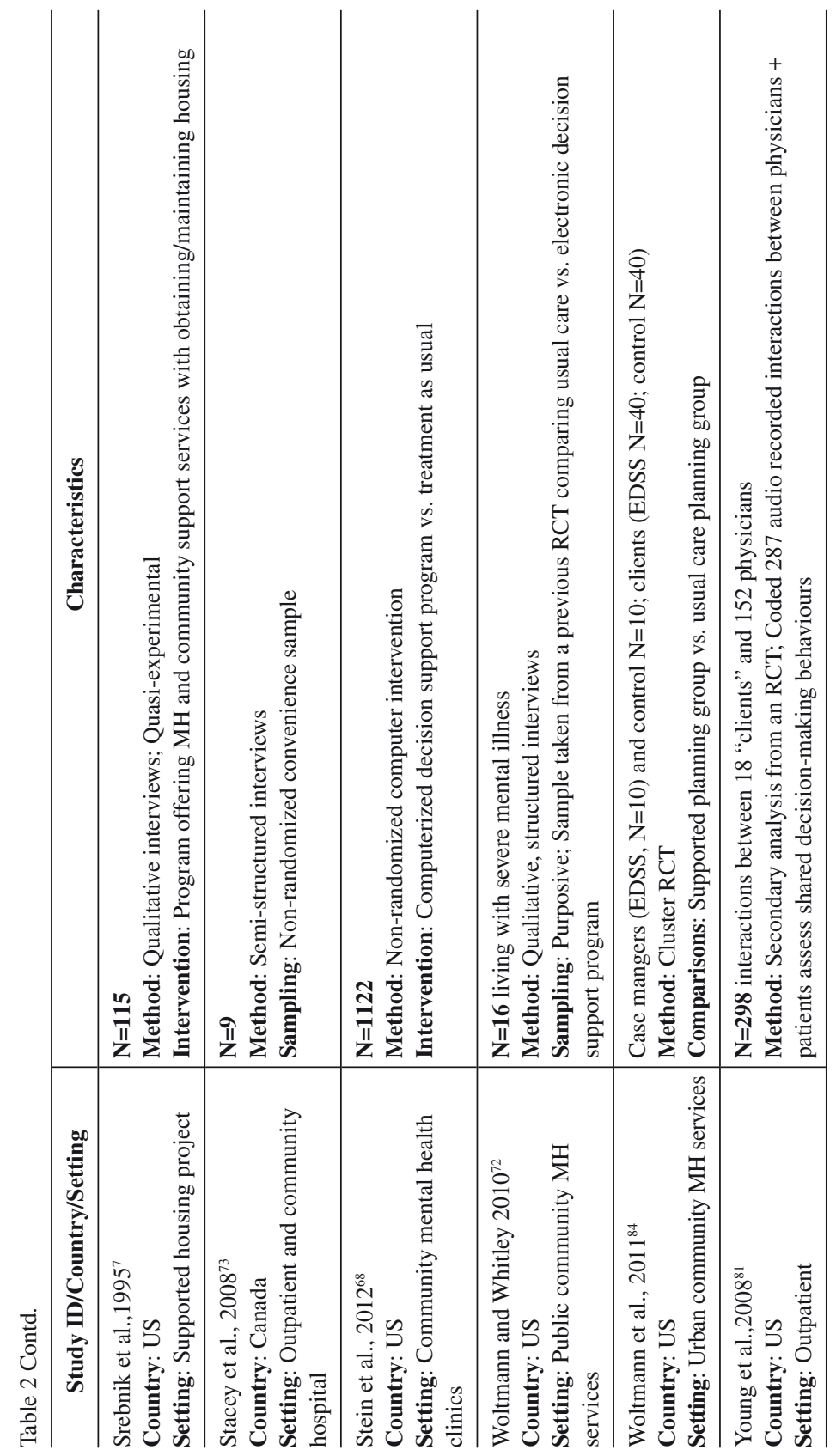


Similarly, Stacey and colleagues found that 52 percent of individuals with depression preferred to make treatment decisions alone, 38 percent collaboratively with the health practitioner, and eight percent wanted the practitioner to make the decision. ${ }^{73}$ In another study, the majority preferred to make their treatment decision alone and have an active role in decisionmaking, followed by sharing the decision with their health care provider, and lastly, very few wanted someone to make a substituted decision on their behalf (even if the substitute decision maker was a family member) ${ }^{71,73}$

More difficult decisions will elicit a need for validation from health care professionals, like hospitalisation. Simon et al. found that participants noticed decision-making took longer when difficult topics arose and when clients were uncertain about the benefits of a decision exceeding the harms (e.g., with medication). ${ }^{74}$ In this particular study, 75 percent of patients reported ambivalence towards decision-making, and judged that when symptoms became too great, decision-making should be placed in the hands of professionals. More difficult personal circumstances of the client (e.g., severity of symptoms at the moment, perceived self-competency, experiences with health care professionals) also play a role in determining whether a client relinquishes decision-making control to the health care professional. ${ }^{75}$

One factor potentially influencing results is treatment setting, that is, whether participants interviewed in these studies were formal or informal patients, outpatients or inpatients. This could influence the results as formal or inpatients may feel they have less options and less autonomy to make decisions, as well as perceived reduced decisional capacity compared to when they voluntarily seek treatment or when receiving care in the community.

The extent to which decision-making will be utilised by patients depends on a number of cognitive and affective factors such as individual preferences regarding involvement in the decision-making process. ${ }^{45} \mathrm{It}$ is not the case that all individuals want to make autonomous decisions, however the central idea is that all individuals should have access to supported decision-making should they need and want it, and all individuals should have the opportunity to exercise their legal capacity. ${ }^{2}$

\section{Barriers to decision-making}

\section{Barriers at the individual level}

First, not being informed and the perceived feeling of not being supported appeared as one barrier in decision-making in mental health care in the literature. Stacey and colleagues found that of 94 participants, 67 were 
uncertain about their decisions regarding medication and treatment, and the uncertain group (compared to those displaying more certainty) felt less informed, less supported and less clear about how to value the benefits and risk of options. ${ }^{73}$ These participants required guidance in acquiring information, clarifying values, and support to reach a decision. Second, some also expressed fear about their own level of competency and were reluctant to breach the topic of shared decision-making with their health providers often relating back to traumatic experiences from the past with health care providers. Another study identified that clients felt particularly uncertain about decision-making when they were perceived to not be competent due to their mental illness. ${ }^{76}$ Third, cultural factors in help-seeking behaviour and decision-making also impact the willingness to share decision-making with health care providers. Patel and Bakken found that Hispanics preferred more passive decision-making in mental health care compared to nonHispanics who preferred a more active decision-making role. ${ }^{71}$ Fourth, social exclusion has also been cited as a barrier to decision-making. ${ }^{60}$ If clients have someone to discuss decisions with (peers, families, community members) this often contributes to mobilising a large proportion of support needed to reach a decision.

Lastly, decisional conflict was cited as a barrier leading to increased treatment discontinuation and treatment refusal. Supported decision-making would contribute to addressing factors that influence decisional conflict such as being uninformed, having unclear values, feeling unsupported, and having low motivation. Another barrier to a more active role for PWMI in treatment decision-making is the fear and anxiety that they are "difficult" patients and challenging their health care provider and this will lead to reduced access to much needed care. ${ }^{67,77}$ Psychoeducation, having peer-staff listen and inform clients, or providing information prior to consultations with health practitioners could alleviating some of this anxiety, fear and insecurity when considering participation in mental health care.

\section{Barriers at the professional level}

For health care workers, a number of barriers to employing a shared decision-making approach have been mentioned in the literature. In line with the patient perception of being perceived as difficult if engaging in shared decision-making behaviours, a trial comparing a shared decisionmaking intervention and treatment as usual by Hamann and colleagues $(2011)^{67}$ found that even at six months post-intervention, although patients in the shared decision-making group had modified their behaviour compared to baseline (more motivated, held different attitudes towards participation 
and decision-making), the treating psychiatrists perceived the shared decision-making group to be more difficult to treat (in terms of stress levels for the psychiatrist) compared to control group patients. Other barriers mentioned have been difficulty in ascertaining how to respond when it comes to mental health crises, lack of system support, and additional time required for shared decision-making. ${ }^{56,58}$ Although other studies, have found that shared decision-making does not require additional time. ${ }^{78,79}$ McMullen found that physicians she interviewed often did not make used of shared decision-making principles, but rather persuaded clients to decide on empirically supported treatments which physicians themselves had some control over (e.g., therapy in their office, pharmacotherapy as administered via their prescription pad). ${ }^{80}$ Two other studies found that most physicians did not try to involve patients in shared decision-making and that physicians failed to fully participate in shared decision-making in consultations. ${ }^{81,82}$

\section{Peer support and support systems}

Two RCTs conducted in Germany revealed that shared decision-making interventions had a marginal increase in patient satisfaction and demonstrated some evidence that shared decision-making also increased doctor facilitation of patient involvement in decision-making, and did not increase doctor consultation time. Neither of the trials found any positive effect of shared decision-making on clinical outcomes, hospital readmission, or patient compliance with treatment. ${ }^{78,79,83} \mathrm{~A}$ more recent RCT found that an electronic decision support system did not increase patient satisfaction, however clients became more involved in treatment plans and case managers became more aware of clients concerns and needs, potentially facilitating a more collaborative and supportive relationship in the future..$^{84}$ Another study had peer-educator led training for people with mental illness, which emphasised informed decision-making, wellbeing, and self-management. ${ }^{85}$ These longterm training sessions resulted in a greater inclination to engage in selfadvocacy behaviours and these effects continued after six months post-intervention as well as across settings and cultures. Advanced directives have also been seen as a way to support the client in reaching a decision and facilitate collaborative partnership between doctors and patients, particularly due to the fact that it takes into account that mental capacity may fluctuate over the course of mental illness. Deegan (2010) found that even within a short 15-minute consultation, peer support and technology could be utilised to enhance psychiatric medication visits and make them more efficient for both patients and clinicians ${ }^{86}$ The drawback to this system is the cost of developing and implementing such a system. 


\section{Supported decision-making in LMICs}

While the literature in HICs is limited, research in LMICs on supported decision-making is even sparser. Poor understanding of patient rights, limited education, and limited medical and legal resources have been reported as reasons for the lack of research ${ }^{87} \mathrm{An}$ opinion piece on advanced directives points towards several implementation barriers in LMICs. ${ }^{50}$ The authors take the view that the service delivery context in a country like India make implementation of supported decision-making tools problematic, as such tools are designed to be implemented in a more accessible, equitable, and organized system. ${ }^{50}$ Another barrier is the limited resource availability for monitoring and evaluating these legislative frameworks leading to potential abuse of such progressive tools deisgned to aid in decision-making and promote autonomy. ${ }^{50}$ Lastly, limited resources means that dedicated legal aid services are scarce, and make implementation of advanced directives in an affordable and accessible manner difficult. ${ }^{50}$ One study countering these opinions was the first study on PADs in India which demonstrated that persons with a chronic mental illness (even with active symptoms) can make use of supportive tools in a resource-poor setting. ${ }^{87}$ While advance directives are not a supportive tool allowing for full autonomous decision-making (although it does fall along the spectrum of support in a supported decisionmaking framework), this trial is a step in the right direction for shifting to more supportive decision-making models in India.

\section{DISCUSSION}

This review aimed to assess progress made in both research and legal domains on supported decision-making models for PWMI. PWMI have a right, like those without a mental illness, to exercise their legal capacity and make decisions in all areas of their lives. The debate surrounding decisionmaking, mental illness, and the right to exercise legal capacity brings up a number of ethical and legal considerations. Part of the complex debate regarding decision-making for PWMI stems from the attribution that PWMI lack mental capacity to make decisions. Indeed, there are periods of time when PWMI may lose capacity to make decisions. Under these circumstances, support measures must be in place to provide all information and guidance necessary to support that person to make an autonomous decision. Support can take on various forms and be directed towards a number of decisions in life, ranging from the mundane to the profound. There is inherently an element of risk for people taking decisions about their own lives ${ }^{88}$; however a supported decision-making paradigm requires 
that choice and risk of making these choices is transparent in order to enable fair appraisal of the decision-making process. ${ }^{88}$

Our findings indicate a disconnect between international conventions (CRPD) and domestic legislation. We found very limited evidence on supported decision-making, and even less evidence on interventions assessing autonomy and decision-making outside treatment decisions. We found that the models of decision-making tested in the research arena are often very narrow and controlled and do not reflect the dynamic relations between health care professionals, legal professionals, clients, and carers that occur in practice. The findings from the research, predominantly on shared decision-making, indicated that common to the majority of PWMI, there is a desire for autonomy in decision-making and support for decisions involving complex life issues, particularly when the person is uncertain about the pros and cons of the decision, or uncertain about their competence. ${ }^{76}$

Some health care providers have expressed concerns about managing capacity and treatment decisions in crises, additional time, resources and infrastructure required, and difficulty in seeing clients as equals; all perceived as barriers to collaborating on decisions. ${ }^{56,58}$ However, supported decisionmaking should not be seen as an impediment to accessing care, but rather a facilitator of better quality care. Supported decision-making as well as shared decision-making for treatment decisions both point towards a model of inclusion, wherein if a person has difficulty in expressing and communicating his or her wishes, the solution is not coercive and involuntary treatment or assignation of guardianship. Instead these methods allow a relationship to develop in ways that make it possible for an individual to communicate what he or she wants in certain aspects of their lives. ${ }^{52}$ It is also important to recognise that there is no "ideal" for supported decision-making either at the professional, state, or national level; but rather a set of components, which, depending on the resources, training and cultural values of the country, can be utilised to promote legal capacity and autonomous decision-making.

From a legal point of view, countries that have ratified the CRPD have a particular impetus to modify or update their mental health legislation in light of the Convention, particularly when it comes to provisions enabling people to exercise their legal capacity. The CRPD requires mental health legislation to be framed in such a way that presumes all PWMI have legal capacity until proven otherwise, and even with a lack of decisional capacity, they should be offered supports and accommodations to reach an autonomous decision.

The lack of legislative frameworks and research evidence suggest that health care professionals, governments, legal systems, and guardians do not always make decisions in accordance with the best interests principle. ${ }^{6}$ 
This provides further impetus to shift from a paternalistic way of viewing PWMI to a more inclusive and supportive system embracing decisions made by PWMI. There is an expectation from the CRPD that governments have a responsibility to change their existing legislation on substitute decision-making and supplant it with a more supportive model encouraging supported decision-making. ${ }^{89}$ Policies and programmes should accordingly be designed to implement such legislation. This depends on how countries interpret Article 12 and interpret support for PWMI. Their interpretations and reaction to these interpretations ultimately shape practices and legislation. ${ }^{6}$ It is therefore important that research be conducted to inform examples of how Article 12 of the CRPD can be implemented, and additionally, governments must liaise with user organisations, peer support networks, carers, and the social sector to ensure that support aids are used in practice when appropriate. ${ }^{89}$ From a practical legislation perspective, instituting a law-based system of supported decision-making should focus on main decisions of legal relevance impacting PWMI, such as finances, who they live with, employment, medical decisions, community participation and choice of appropriate support services. ${ }^{11}$ The key for legislation is to make provisions which enable support to individuals in a way that encourages them to utilise existing support networks and access support when they feel it is necessary to reach a decision. ${ }^{11}$

\section{ADAPTING SUPPORT MODELS TO LMICS}

Several countries discussed in this paper, such as the UK, Canada, Sweden and Australia, are leading the way towards inclusion of supported decisionmaking in their legislation and other countries could look to these examples to identify applicable components to their own context and legal systems. LMICs particularly need research and applicable models in supported decision-making. To illustrate, a review of shared decision-making training programs globally found no evidence of programs in LMICs to train health professionals in shared decision-making..$^{90}$ The question remains as to how supported decision-making models can be feasible for clinicians and clients, and adapted to suit the legal and medical context in LMICs.

The first issue for LMICs is re-conceptualising decision-making capacity for PWMI. For example, in a number of African countries, decision-making capacity is viewed as an all or nothing phenomenon. This means that PWMI when stripped of decision-making powers, lose the ability to make decisions in all areas of their lives and rarely have an opportunity for re-assessment of capacity to change this status. ${ }^{91}$ Another issue is the potential for abusing 
supported decision-making efforts, as a person providing support may use their influence over the PWMI in a way that may not be in accordance with the best interests of the PWMI. ${ }^{70}$ In LMICs, there is limited availability of monitoring systems in place to pose a safeguard against such abuse, however, non-profit organisations could perhaps enlist a guardian monitoring service. An additional consideration is, in resource-constrained settings (especially in LMICs) how and from whom can support be provided in the absence of family and friends? This is particularly the case, in both HICs and LMICs, for PWMI who have been institutionalised for a significant period of time in psychiatric hospitals and have limited community support. How can supported decision-making tools be extended to this population? The Australian supported decision-making study found that a number of people wanted support in making decisions but did not have the network to do so. Gordon discusses how community advocacy organisations have previously experimented with the development of support networks for people without family and friends who are willing or able to provide support and how the organizations can continue to do so. While this is a very positive initiative, Gordon expresses concern as to how sustainable it is to expect that nonprofit organizations can handle large incoming caseloads of PWMI requiring support. ${ }^{57}$

The second issue when adapting models from HICs is the limited financial resources in LMICs. A personal ombudsman model like in Sweden may not be feasible in a LMIC due to the high implementation costs. Family support is crucial in LMICs and can provide a unique opportunity when considering appropriate supported decision-making models. However, despite the limited financial resources, there are ways that LMICs can provide support for people to exercise their legal capacity. It is plausible that placing emphasis on the role of families and support networks in decision-making, similar to the UK, could be beneficial in LMICs, both from a cultural and financial standpoint. Involving independent advocates, where financially feasible (perhaps from voluntary organizations in LMICs) could potentially alleviate the barrier of social exclusion that limits support for PWMI who do not have a carer or support network. This is an effective model that works in the UK ${ }^{88}$ It would also be necessary for the legal system or for an independent body to monitor this informal support to ensure that the client is making autonomous decisions and that their human rights are respected.

Brayley proposes a model of supported decision-making based on a spectrum of increasing or decreasing state intervention and autonomy. ${ }^{57}$ The model "steps up" options for care and intervention offered by the state, depending on need. The highest state intervention involves the appointment 
of a state official as a guardian of last resort, whereas the step with the lowest state intervention is autonomous decision-making. Steps in between involve: a support team assisting with decision-making; single one-off decisions being made by a tribunal (wherein the client retains decision-making power for all other matters with the exception of this one-off decision); enduring guardianship, which the client sets out prior to losing capacity; guardianship by a family or friend with government support or overview. This is similar to a sliding scale of support, which would be beneficial in LMICs but also in HICs. Offering a number of support mechanisms on a spectrum based on need, and based on existing resources of the state or country and which build upon the values of the given society would be most effective to accommodate diverse needs of people with disabilities. In addition, particularly in LMICs, but not exclusively, people turn to informal support networks when they realise they need support. ${ }^{11}$ As a result, peers and social networks can be invaluable in providing accommodations and support to those who would like to reach a decision while also utilising existing resources in a country and when the addition of legal advocates and representatives might be costly, particularly in resource-constrained settings. This could entail training people on the path to recovery from mental illness in peer-support training who can provide support or resources to those who require it to make decisions. This would indeed translate action to implementation of Article 12 of the CRPD by strengthening and extending informal networks rather than substituting them with professional legal and medical services. ${ }^{11}$

There is no single best practice for supporting people with disabilities to reach decisions, as systemic factors impact the provisions of these accommodations (resources, legal system, implementation of legislative frameworks, availability of support networks) as well as individual factors (level of need of the individual, accessibility to support networks and services, capacity at the time of need). Furthermore, the decision-making process in mental illness is complex (largely due to the chronicity and course of illness) and dependent on circumstances and context. However, certain components from successful models that embody the support paradigm, as well as a social model of disability, could be extracted and utilised in systems and settings wishing to shift away from a guardianship model. It is therefore important that research pinpoints components of supported decision-making which facilitate exercising legal capacity but which could be used in different countries, and then tailored to reflect the context. Research is therefore urgently needed in light of the fact that guidelines, policies and international conventions like the CPRD advocate for supported decision-making, with little evidence of effect. ${ }^{26}$ 


\section{LIMITATIONS}

There are of course limitations of this paper that need to be addressed. Perhaps most importantly, the terminology of decision-making is highly heterogeneous and loosely defined, impacting the results of our review with regards to the numbers of included studies. It is possible we may have missed a number of studies due to our search terms. For example, we did not look at patient participation in mental health care as a search term, which could have yielded some studies focusing on shared decisionmaking. Our hand search identified a number of more relevant studies than did our database searches, potentially due to the grey literature, which we included in the legislative review. In addition, the reviewed literature was primarily observational or pilot studies with a small, narrowly focused sample size, which is not generalizable to the wider population.

There is a substantial gap between supported decision-making models and actual practice; actual decision-making process rarely fits any of these idealised models.$^{80}$ Similarly, while there is no problem in understanding the ideals of Article 12 of the CPRD, truly shifting from substitute decisionmaking to a more supportive mode is an entirely different problem. ${ }^{6}$ Selection of a decision-making model depends on the circumstances of the decision that is being made, the preferences of the clients, other relevant parties, and based on available information. An illustrative example is a consumer health survey which found that although a large majority of respondents did not endorse health care professionals to solely make decisions; general practitioners conversely believed that their task was to relieve patient anxiety and comply with patient expectations rather than involve them in the decision-making process. ${ }^{80}$ Third, in many settings, to provide supported decision-making options for clients, it is necessary that there is a paradigm shift to approach disability from a social model, ${ }^{62,63}$ involving the assumption that people with disabilities have the capacity to make their own decisions.

\section{CONCLUSION}

The paucity of research in supported decision-making models for PWMI highlights the need for tested models, not only in HICs, but also in LMICs. Furthermore, we note that in order for the ability to exercise legal capacity to become a lived reality for PWMI, there is a need for more research assessing which components of supported decision-making could be used in legislation and in practice. A disconnect still exists between national and/ 
or state legislation and the CRPD provisions. While a government may be in favour of the idea of supported decision-making, their mental health and/ or guardianship legislation is often not conducive to exercising legal capacity. It is important that mental health laws be updated to reflect CRPD provisions, as mental health legislation can shape, empower, and regulate the entire mental health system, including services, policies, and relationships between professionals and end users. ${ }^{5}$

\title{
Acronyms List:
}

$\mathrm{CRPD}=$ The Convention on the Rights of Persons with Disabilities

HICs = high-income countries

LMICs $=$ low- and middle-income countries

PADs $=$ psychiatric advance directives

$\mathrm{PWD}=$ persons with disabilities

PWMI $=$ persons with mental illness

$\mathrm{RCT}=$ randomized control trial

\begin{abstract}
About the Authors: Dr. Soumitra Pathare is involved in the mental health law reform process in India. Since 2010, he has provided technical assistance to the Ministry of Health and Family Welfare, Government of India in drafting the new mental health legislation. He is a member of the Mental Health Policy Group appointed by the Ministry of Health and Family Welfare, Government of India to draft India's first national mental health policy. He is also the course director of the International Diploma in Mental Health Law and Human Rights run by the Indian Law Society in collaboration with the World Health Organization.

Laura Shields is a Researcher and Lecturer at the Athena Institute, VU University Amsterdam, Netherlands, and a Research Fellow at the Centre for Mental Health Law and Policy, Indian Law Society in Pune, India. She is currently working on completing her $\mathrm{PhD}$ on mental health capacity building in India from a health systems and rights-based perspective.
\end{abstract}

Conflicts of Interest: None declared.

\section{REFERENCES}

1. Commissioner for Human Rights. Who gets to decide? Right to legal capacity for persons with intellectual and psychosocial disabilities. Strasbourg, France: CommDH/Issue Paper. Council of Europe; 20 February 2012.

2. Dhanda A. Legal capacity in the disability rights convention: stranglehold of the past or lodestar for the future? Syracuse J Int Law Commerce. 2007;34:429-62.

3. Bach M. Supported decision making under Article 12 of the UN Convention on the Rights of Persons with Disabilities: questions and challenges. Athlone, Ireland: Parents' Committee of Inclusion Ireland; 3 November 2007. 
4. Lawson A. The United Nations Convention on the Rights of Persons with Disabilities: new era or false dawn? Syracuse J Int Law Commerce. 2007;34: 563-620.

5. McSherry B. Rethinking mental health laws: international trends. Samos Island, Greece: 12th Greek/Australian International Legal and Medical Conference; 4 June 2009.

6. Dinerstein RD. Implementing legal capacity under Article 12 of the UN Convention on the Rights of Persons with Disabilities: the difficult road from guardianship to supported decision-making. Human Rights Brief. 2012;19:812.

7. Srebnik D, Livingston J, Gordon L, King D. Housing choice and community success for individuals with serious and persistent mental illness. Community Ment Health J. 1995;31:139-52.

8. Rose S, Black B. Advocacy and Empowerment: Mental Health Care in the Community. Boston, MA: Routledge \& Kegan Paul; 1985.

9. Law Commission of Ontario. Protecting autonomy and the equal right to legal capacity in the face of serious adverse effects. Chapter VI. Available from URL: http://www.lco-cdo.org/en/disabilities-call-for-papers-bach-kerznerpartII-sectionVI (Accessed 3 December 2012).

10. Inclusion Europe. Legal Capacity. Available from URL: http://inclusion-europe. org/en/policies/legal-capacity (Accessed 3 December 2012).

11. Inclusion International. Key elements of a system for supported decisionmaking: position paper of inclusion international, to be adopted at the General Assembly 2008.

12. Minkowitz T. Legal capacity in CRPD and its implications for older persons. Presentation at the Expert Group Meeting on the Human Rights of Older Persons. New York, NY: United Nations Headquarters (OHCHR and UNDESA); 29-31 May 2012. Available from URL: http://social.un.org/ ageing-working-group/documents/egm/Session\%25202_

Tina\%2520Minkowitz.pdf (Accessed 3 December 2012).

13. Quinn G. Rethinking personhood: new directions in legal capacity law and policy or how to put the 'shift' back into paradigm shift. Paper presented at 'In from the margins': New Foundations for Personhood and Legal Capacity in the 21st Century. Vancouver, Canada: University of British Columbia; 2011.

14. Convention on the Rights of Persons with Disabilities, 2006. Adopted 13 December 2006, UNGA Res. 61/106 and Optional Protocol to the Convention on the Rights of Persons with Disabilities. 13 December 2006, UNGA Res. 61/6 11 .

15. Quinn G. Personhood \& legal capacity: perspectives on the paradigm shift of Article 12 CRPD. Concept Paper. Boston, MA: HPOD Conference, Harvard Law School; 20 February 2010. 
16. Theytaz-Bergman L, Tromel S. Guidance document: effective use of international human rights monitoring mechanisms to protect the rights of persons with disabilities. Geneva, Switzerland: International Disability Alliance; 2010. Available from URL: http://www.riglobal.org/wp-content/ uploads/2010/11/CRPD-Guidance-Document-English_IDA_May10-1.doc (Accessed 3 December 2012).

17. Mental Disability Advocacy Center (MDAC). Supported decision-making: an alternative to guardianship. Policy Paper. Available from URL: http://www. mdac.info/en/resources?goal=137\&format=146 (Accessed 3 December 2012).

18. Office of the United Nations High Commissioner for Human Rights. Legal capacity. August 2005. Background conference document. Available from URL: http://www2.ohchr.org/SPdocs/CRPD/DGD21102009/OHCHR_BP_ Legal_Capacity.doc. (Accessed 3 December 2012).

19. Fennell P, Khaliq U. Conflicting or complementary obligations? The UN Disability Rights Convention, the European Convention on the Human Rights and English law. European Human Rights Law Review. 2011;2:33-45.

20. Salzman L. Guardianship for persons with mental illness - a legal and appropriate alternative? St Louis University J Health Law Policy. 2011;4:279329. Available from URL: http://slu.edu/Documents/law/SLUJHP/Salzman_ Article.pdf (Accessed 3 December 2012).

21. Goins M, Good K, Harley C. Perceiving Others as Different: A discussion on the stigmatization of the mentally ill. Ann Health Law. 2010;19:441-7.

22. Wahl OF. Stigma as a barrier to recovery from mental illness. Trends Cogn Sci. 2012;16:9-10.

23. Bach M, Kerzner L. A new paradigm for protecting autonomy and the right to legal capacity. Ontario, Canada: Prepared for the Law Commission of Ontario; October 2010. Available from URL: http://www.lco-cdo.org/disabilities/bachkerzner.pdf (Accessed 3 December 2012).

24. World Health Organization. WHO Resource Book on mental health, human rights and legislation. Geneva, Switzerland: WHO; 2005.

25. Clayman ML, Makoul G. Conceptual variation and iteration in SDM: the need for clarity. In: Edwards A, Elwyn G, (editors). Shared Decision-Making in Health Care. Achieving Evidence-Based Patient Choice. 2nd Edition. Oxford, UK: Oxford University Press; 2009. p.109-16.

26. Duncan E, Best C, Hagen S. Shared decision making interventions for people with mental health conditions. Cochrane Database Syst Rev. 2010;1:C007297.

27. Charles C, Gafni A, Whelan T. Shared decision making in the medical encounter: what does it mean? (Or, it takes at least two to tango). Soc Sci Med. 1997;44:681-92.

28. Charles C, Gafni A, Whelan T. Decision-making in the physician-patient encounter: revisiting the shared treatment decision-making model. Soc Sci Med. 1999;49:651-61.

29. Coulter A. Partnerships with patients: the pros and cons of shared decision making. J Health Serv Res Policy. 1997;2:112-21. 
30. Elwyn G, Edwards A, Gwyn R, Grol R. Towards a feasible model for shared decision making: Focus group study with general practice registrars. BMJ. 1999;319:753-6.

31. Elwyn G, Edwards A, Kinnersley P, Grol R. Shared decision making and the concept of equipoise: the competences of involving patients in healthcare choices. Br J Gen Pract. 2000;50:892-9.

32. Towle A, Godolphin W. Framework for teaching and learning informed shared decision-making. BMJ.1999;319:766-71.

33. Trevene L, Barratt A. Integrated decision making: definitions for a new discipline. Patient Educ Couns. 2003;50:265-8.

34. Wills CE, Holmes-Rovner M. Integrating decision making and mental health interventions research: research directions. Clin Psychol (New York). 2006; 13:9-25.

35. Patel SR, Bakken, S, Ruland C. Recent advances in shared decision making for mental health. Curr Opin Psychiatry. 2008;21:606-12.

36. Mueser K, Corrigan P, Hilton D, Tanzman B, Schaub A, Gingerich S, et al. Illness management and recovery for severe mental illness: a review of the research. Psychiatr Serv. 2002;53:1272-84.

37. Deegan PE, Drake RE. Shared decision making and medication management in the recovery process. Psychiatr Serv. 2006;57:1636-9.

38. Mistler LA, Drake RE. Shared decision making in antipsychotic management. J Psychiatr Pract. 2008;14:333-44.

39. Adams JR, Drake RE. Shared decision-making and evidence-based practice. Community Ment Health J. 2006;42:87-105.

40. Noble LM, Douglas BC. What users and relatives want from mental health services. Curr Opin Psychiatry. 2004;17:289-96.

41. Joosten EA, DeFuentes-Merillas L, de Weert GH, Sensky T, van der Staak CP, de Jong CA. Systematic review of the effects of shared decision-making on patient satisfaction, treatment adherence and health status. Psychother Psychosom. 2008;77:219-26.

42. Makoul G, Clayman ML. An integrative model of shared decision making in medical encounters. Patient Educ Couns. 2006;60:301-12.

43. Montori V, Gafni A, Charles C. A shared treatment decision making approach between patients with chronic conditions and their clinicians: the case of diabetes. Health Expect. 2006;9:25-36.

44. Adams JR, Drake RE, Wolford GL. Shared decision-making preferences of people with severe mental illness. Psychiatr Serv. 2007;58:1219-21.

45. Cooper LA. At the centre of decision making in mental health services and interventions research: patients, clinicians, or relationships? Clin Psychol: Society Practice. 2006:13:26-9.

46. Malm W, Ivarsson B, Allebeck P, Falloon, IRH. Integrated care in schizophrenia: a 2-year randomized controlled study of two community based treatment programs. Acta Psychiatr Scand. 2003;107:415-23. 
47. Raue PJ, Schulberg HC, Heo M, Kilmstra S, Bruce ML. Patients' depression treatment preferences and initiation, adherence and outcome: a randomized primary care study. Psychiatr Serv. 2009;60:337-43.

48. Raue PJ, Schulberg HC, Lewis-Fernandez R, Boutin-Foster C, Hoffman AS, Bruce ML. Shared decision-making in the primary car treatment of late life major depression: a needed new intervention? Int J Geriatr Psychiatry. 2010; 25:1101-11.

49. Campbell LA, Kisely, SR. Advanced treatment directives for people with severe mental illness. Cochrane Database Syst Rev. 2009;21:CD005963.

50. Sarin A, Murthy P, Chatterjee S. Psychiatric Advanced directives: Potential challenges in India. Indian J Med Ethics. 2012;9:104-7.

51. Honberg RS. Advance Directives. National Alliance on Mental Illness. Journal of NAMI California, Mental Illness and Law. Undated;11(3). Available from URL: http://www.nami.org/Content/ContentGroups/Legal/Advance_Directives.htm (Accessed 3 December 2012).

52. Minkowitz T. The paradigm of supported decision making. Available from URL: http://www.chrusp.org/media/AA/AG/chrusp-biz/downloads/29411/ Minkowitz_presentation.ppt (Accessed 3 December 2012).

53. Weller P. Developing law and ethics: The Convention on the Rights of Persons with Disabilities. Alternative Law J. 2010;35:8-12.

54. Mental Disability Advocacy Center. Czech Republic enacts legal capacity law reform. 21 February 2012. Available from URL: http://www.mdac.info/en/ news/czech-republic-enacts-legal-capacity-law-reform (Accessed 3 December 2012).

55. Mental Disability Advocacy Center. Hungary: Parliament reforms legal capacity laws. 22 September 2009. Available from URL: http://www.mdac.info/en/ hungary-parliament-reforms-legal-capacity-laws (Accessed 5 December 2012).

56. Mental Disability Advocacy Center. Constitutional court undermines legal status of Hungarians with disabilities. 27 April 2010. Available from URL: http://www.mdac.info/en/constitutional-court-undermines-legal-statushunga (Accessed 5 December 2012).

57. Gordon RM. The emergence of assisted (supported) decision-making in the Canadian law of adult guardianship and substitute decision-making. Int $\mathbf{J}$ Law Psychiatry. 2000;23:61-77.

58. David MS. Legal guardianship of individuals incapacitated by mental illness: where do we draw the line? Suffolk U Law Rev. 2012;45:465-96.

59. Marson DC, Savage R, Phillips J. Financial capacity in persons with schizophrenia and serious mental illness: Clinical and research ethics aspects. Schizophr Bull. 2006;32:81-91.

60. Office of the Public Advocate. South Australian Supported Decision Making Project: October 2012 update. Australia. Available from URL: http://www. opa.sa.gov.au/cgi-bin/wf.pl?pid=\&mode=cd\&file=../html/documents $/ / 11_{\text {_ }}$ Supported\%20Decision\%20Making (Accessed 5 December 2012). 
61. Carter B. Supported decision-making: Background and discussion paper. Victoria, Australia: Office of the Public Advocate; November 2009. Available from URL: http://www.publicadvocate.vic.gov.au/file/file/Research/Discussion/ 2009/0909_Supported_Decision_Making.pdf (Accessed 5 December 2012).

62. Amnesty International. Decision-making capacity in mental health: exploratory research into the views of people with personal experience. Ireland: Amnesty International Ireland; December 2009.

63. McDaid S, Delaney S. A social approach to decision-making capacity: exploratory research with people with experience of mental health treatment. Disability Society. 2011:26;729-42.

64. Joosten EA, de Jong CA, de Weet-van Oene GH, Sensky T, van der Staak CP. Shared decision-making reduces drug use and psychiatric severity in substance-dependent patients. Psychother Psychosom. 2009;78:245-53.

65. Mahone I. Shared decision making and serious mental illness. Arch Psychiatr Nurs. 2008;22:334-43.

66. Hamera E, Pallikkthayil L, Baker D, White D. Descriptive study of shared decision making about lifestyle modifications with individuals who have psychiatric disabilities. J Am Psychiatr Nurses Assoc. 2010;16:280-7.

67. Hamann J, Mendel, R, Meier A, Asani F, Pausch, E, et al. How to speak to your psychiatrist: shared decision-making training for inpatients with schizophrenia. Psychiatr Serv. 2011;62:1218-21.

68. Stein BD, Kogan JN, Mihalyo MJ, Schuster J, Deegan PE, et al. Use of a computerized medication shared decision-making tool in community mental health settings: impact on psychotropic medication adherence. Community Men Health J. July 2012: epub ahead of print.

69. Hamann J, Cohen R, Leucht S, Busch R, Kissling W. Do patients with schizophrenia wish to be involved in decisions about their medical treatment? Am J Psychiatry. 2005;162:2382-4.

70. O’Neal EK, Adams JR, McHugo,GJ, Van Citters AD, Drake RE, Bartels SJ. Preferences of older and younger adults with serious mental illness for involvement in decision-making in medical and psychiatric settings. Am J Geriatr Psychiatry. 2008;16:826-33.

71. Patel SR, Bakken S. Preferences for participation in decision making among ethnically diverse patients with anxiety and depression. Community Ment Health J. 2010; 46:466-73.

72. Woltmann E, Whitley R. Shared decision making in public mental health care: perspectives form consumers living with severe mental illness. Psychiatr Rehabil J. 2010;34:29-36.

73. Stacey D, Menard P, Gaboury I, Jacobsen M, Sharif F, et al. Decision-making needs of patients with depression: a descriptive study. J Psychiatr Ment Health Nurs. 2008; 15:287-95.

74. Simon D, Loh A, Wills CE, Harter M. Depressed patient's perceptions of depression treatment decision-making. Health Expectations. 2006;10:62-74. 
75. Campbell SM, Gately C, Gask L. Identifying the patient perspective of the quality of mental healthcare for common chronic problems: a qualitative study. Chronic Illn. 2007;3:46-65.

76. Mahone IH, Farrell S, Hinton I, Johnson R, Moody D, et al. Shared decision making in mental health treatment: qualitative findings from stakeholder focus groups. Arch Psychiatr Nurs. 2011;25:e27-36.

77. Lester H, Tait L, England E, Tritter J. Patient involvement in primary care mental health: a focus group study. Br J Gen Pract. 2006;56:415-22.

78. Loh A, Simon D, Wills CE, Kriston L, Niebling W, Harter M. The effects of shared decision-making intervention in primary care of depression: A clusterrandomized controlled trial. Patient Educ Couns. 2007;67:324-32.

79. Hamann J, Langer B, Winkler V, Busch R, Cohen R, et al. Shared decision making for in-patients with schizophrenia. Acta Psychiatr Scand. 2006;114: 265-73.

80. McMullen LM. Discourses of influence and autonomy in physicians' accounts of treatment decision making for depression. Qual Health Res. 2012;22:238-49.

81. Young HN, Bell RA, Epstein, RM, Feldman, MD, Kravitz RL. Physicians' shared decision-making behaviours in depression care. Arch Intern Med. 2008;168:1404-8.

82. Loh A, Simon D, Hennig K, Hennig B, Harter M, Elwyn G. The assessment of depressive patients' involvement in decision making in audio-taped primary care consultation. Patient Educ Couns. 2006;63:314-8.

83. Hamann J, Cohen R, Leucht S, Busch R, Kissling W. Shared decision making and long-term outcome in schizophrenia treatment. J Clin Psychiatry. 2007; 68:992-7.

84. Woltmann EM, Wilkniss SM, Teachout A, McHugo GJ, Drake RE. Trial of an electronic decision support system to facilitate shared decision-making in community mental health. Psychiatr Serv. 2011;62:54-60.

85. Jonikas JA, Gret DD, Copeland ME, Razzano LA, Hamilton MM, et al. Improving propensity for patient self-advocacy through wellness recovery action planning: results of a randomized controlled trial. Community Ment Health J. December 2011: epub ahead of print.

86. Deegan PE. A web application to support recovery and shared decision making in psychiatric medication clinics. Psychiatr Rehabil J. 2010;34:23-8.

87. Kumar TC, John S, Gopal S, Mohan G, Joseph J, Rangaswamy T. PAS study group. Psychiatric advance statements: an Indian experience. Int J Soc Psychiatry. April 2012: epub ahead of print.

88. Department of Health. Independence, choice and risk: a guide to best practice in supported decision-making. London, England: DHUK; May 2007. Available from URL: http://www.dh.gov.uk/en/Publicationsandstatistics/Publications/ PublicationsPolicyAndGuidance/DH_074773 (Accessed 5 December 2012).

89. United Nations Enable. Chapter Six: From provisions to practice: implementing the Convention. 2012. Available from URL: http://www.un.org/disabilities/ default.asp?id=17 (Accessed 5 December 2012). 
90. Legare F, Politi MC, Drolen R, Desroches S, Stacey D, et al. Training health professionals in shared decision-making: an international environmental scan. Patient Educ Couns.2012;88:159-69.

91. Bartlett P, Hamzic V. Reforming mental disability law in Africa: practical tips and suggestions. Prepared for the Nuffield Foundation. Human Rights law Centre, University of Nottingham, England. 2010.

92. International Guardianship Network. Resource for Second World Congress on Adult Guardianship. Available from URL: http://www.internationalguardianship.com/guardianship.htm (Accessed 3 December 2012).

93. Brandstätter A. Personal decision making: towards a paradigm-shift in Austria. Lebensilfe Osterreich; undated. [In German]

94. Brayley J. Supported Decision making in Australia. Presentation notes. Presented in Melbourne, 14 December 2009. Presentation delivered at the Victoria Office of the Public Advocate, Australia.

95. Government of Victoria. Exposure Draft Mental Health Bill 2010. Information sheet 1: supported decision-making, improving patient participation and carer involvement. Department of Health, State Government of Victoria, Australia.

96. Wolstenholme M. Current trends in mental health legislation. Department of Health, Mental Health Commission, Government of Western Australia.

97. Quinn M. Mental health and human rights in Victoria. Right Now, Human Rights in Australia. 20 May 2011. Available from URL: http://rightnow.org. au/topics/disability/mental-health-and-human-rights-in-victoria/ (Accessed 5 December 2012).

98. Victorian government. Chapter 9: Co-decision making. Victorian Government of Australia Law Reform. Guardianship Report. Available from URL: http:// www.lawreform.vic.gov.au/sites/default/files/Guardianship_FinalReport_ Ch\%209_Co-decision\%20making.pdf (Accessed 5 December 2012).

99. Office of the Public Advocate, South Australia. Supported decision-making. Available from URL: http://www.publicadvocate.vic.gov.au (Accessed 5 December 2012).

100. Friday S. Vancouver/Richmond mental health network society representation agreements and supported decision-making. Ontario, Canada: Canadian Coalition of Alternative Mental Health Resources; May 2005. Available from URL: http://ccamhr.ca/communications/repaggreements.html (Accessed 5 December 2012).

101. Surtees D. The evolution of co-decision-making in Saskatchewan. Saskatchewan Law Rev. 2010;73:75-92.

102. Government of Alberta. The Mental Health Act and Adult Guardianship and Trusteeship Act. Fact Sheet. 2009/2010. OPG5632. Available from URL: http://www.albertahealthservices.ca/hp/if-hp-agta-mha-fact-sheet.pdf (Accessed 5 December 2012).

103. Kerzner L. Paving the way to full realization of the CRPD's rights to legal capacity and supported decision-making: a Canadian perspective. Canada: April 2011. Available from URL: http://cic.arts.ubc.ca/research-knowledgeexchange/supportive-decision-making.html (Accessed 5 December 2012). 
104. Burningham S. Developments in Canadian adult guardianship and co-decisionmaking law. Dalhousie J Legal Studies. 2009;18:119.

105. Handicap International. Making it work: Colombia. Making it work: good practices for disability inclusive development. Available from URL: http:// www.makingitwork-crpd.org/miw-initiatives/south-america/colombia/ (Accessed 5 December 2012).

106. Blankman K. Guardianship models in the Netherlands and Western Europe. Int J Law Psychiatry. 1997;20:47-57.

107. European Court of Human Rights. Amicus Brief. Application No. 13469/06. D.D. v. Lithuania. Written comments by the European Group of National Human Rights Institutions. Pursuant to Article 352 of the European Convention on Human Rights and Rule 442 of the Rules of the European Court of Human Rights; 22 April 2008.

108. Boyle G. The Mental Capacity Act 2005: promoting the citizenship of people with dementia? Health Soc Care Community. 2008;16:529-37.

109. Fulton K, Woodley K, Sanderson H. Supported decision making: a guide for supporters. United Kingdom: Paradigm; 2008. Available from URL: http:// www.paradigm-uk.org/Resources/9/2/9/Supported\%20Decision\%20Making \%20(Final\%20Online\%20Version).pdf (Accessed 5 December 2012).

110. Ministry of Health and Family Welfare, Government of India. Draft Mental Health Care Bill. 2011. National Mental Health Programme, Government of India, Delhi, India. Available from URL: http://www.mohfw.nic.in/index1.php ?lang=1\&level=2\&sublinkid=310\&lid=310 (Accessed 5 December 2012).

111. Patrick H. Assisted decision-making: a legal response. Association of Law Reform Agencies of Eastern and Southern Africa (Alraesa) Alraesa law Reform Conference: March 2005.

112. PO-Skåne. Sweden. Available from URL: http://www.po-skane.org (Accessed 5 December 2012). [In Swedish]

113. Alzheimer Europe. Switzerland: legal capacity and proxy decision-making: Issues surrounding loss of legal capacity. Available from URL: http://www. alzheimer-europe.org/Policy-in-Practice2/Country-comparisons/Legalcapacity-and-proxy-decision-making/Switzerland (Accessed 5 December 2012).

114. Federal Department of Justice and Police. Bills still under discussion, Revision of guardianship legislation. Confederation of Switzerland. Available from URL: http://www.ejpd.admin.ch/content/ejpd/en/home/themen/gesellschaft/ ref_gesetzgebung/ref_vormundschaft.html (Accessed 5 December 2012).

115. National Resource Center on Psychiatric Advance Directives (NRC-PAD). Available from URL: http://www.nrc-pad.org/ (Accessed 5 December 2012).

116. Henderson C, Swanson JW, Szmukler G, Thornicroft G, Zinkler M. A typology of advance statements in mental health care. Psychiatr Serv. 2008;59:63-71. 